EISSN: 2706 -7947 ISSN: 2077- 4613

DOI: 10.36632/mejas/2021.11.4.72

Journal homepage: www.curresweb.com

Pages: 933-941

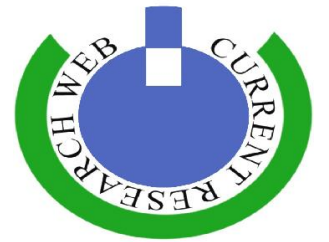

\title{
In vitro evaluation of the antiviral activity and detection of the enterocin coding genes of the probiotic bacterium Enterococcus faecium NM213
}

\author{
Nahla M. Mansour'1, Hayam Mansour², Ahmed I. Abd El Naem ${ }^{3}$ and Waled M Elsenousy ${ }^{4}$ \\ ${ }^{1}$ Chemistry of Natural and Microbial Products Dept., Pharmaceutical and Drug Industries Research \\ Institute, National Research Centre, 33 El Buhouth St., Dokki, P.O. Box: 12622, Egypt. \\ ${ }^{2}$ Cell Biology Dept., Biotechnology Research Institute, National Research Centre, 33 El Buhouth St., \\ Dokki, P.O. Box: 12622, Egypt. \\ ${ }^{3}$ Molecular Genetics and Enzymology Dept., Human Genetics and Genome Research Institute, \\ Division, National Research Centre, 33 El Bohouth St., Dokki, P.O. Box: 12622, Egypt. \\ ${ }^{4}$ Water Pollution Research Dept., Environmental and Climate Change Research Institute, National \\ Research Centre, Egypt.
}

Received: 10 Oct. $2021 \quad$ Accepted: 14 Nov. $2021 \quad$ Published: 20 Nov. 2021

\begin{abstract}
There is a growing concern globally due to the increasing spread of the resistance to current antiviral drugs which lead to innovative and discovery novel alternative antiviral means. Probiotics in particular Lactic acid bacteria (LAB) have been recognized recently as antiviral candidates via direct interaction with the virus, producing inhibitor substances or through modulation of the immune system. Here we represent, the antiviral activity of our probiotic Enterococcus faecium NM213 against four major human enteroviruses; Coxsackie B4, Hepatitis A Virus (HAV) Strain HM175, rotavirus Wa strain, and herpes simplex virus type-1 (HSV-1). The assessment was done in vitro by means of four different kidney and liver cell lines. In addition, the NM213 strain was screened for the presence of the enterocin encoding genes by PCR and sequencing. The results showed the significant ability of the cell-free supernatant (CFS) of NM213 in reduction of (HSV-1), HAV HM 175, Coxsackie (B4), and rotavirus (Wa) by 70\%, $60 \%, 53.3 \%$, and $50 \%$ respectively while its cell extract (CE) showed a fewer reduction to the four viruses by $20 \%, 10 \%, 10 \%$, and $20 \%$ in turn while neither PBS buffer nor MRS broth showed any antiviral activity or cytotoxicity effect. Screen the presence of enterocin by PCR and sequencing the amplified fragments revealed the presence of enterocin A and B which encoded by ent $\mathrm{A}$ and ent $\mathrm{B}$ genes. Further molecular characterization for such valuable enterococci NM213 will be conducted in particular achieving a complete genome sequence to present it for commercial and applied purposes.
\end{abstract}

Keywords: Coxsackie virus, Enterococcus, Herpes simplex virus, Probiotics, Rotavirus

\section{List of Abbreviations:}

CFS, Cell free supernatant; CE, Cell extract; DMEM, Dulbecco's Modified Eagle Medium; ent A, Enterocins A; ent B, Enterocins B; E. faecium, Enterococcus faecium

\section{Introduction}

The genus Enterococcus is a candidate of lactic acid bacteria (LAB) group and forms a significant portion of human normal microbiota especially the gastrointestinal tract (GIT) in addition to other niches in mouth and on skin. These microbes are found also globally in an enormous diversity of vegetables, meats, dairy products and processed food (Devriese et al., 1995; Pesavento et al., 2014; Gomes et al., 2008). Although Enterococcus are not generally regarded as safe (GRAS) by Food Drug Administration FDA but many strains are measured as non-pathogenic and have been implemented as

Corresponding Author: Nahla Mansour. Gut Microbiology \& Immunology Group, Chemistry of Natural and Microbial Products Dept., Pharmaceutical and Drug Industries Research Institute, National Research Centre, 33 El Buhouth St., Dokki, P.O. Box: 12622, Egypt. E-mail: nahla_mansour@hotmail.com,nm.hassanein@nrc.sci.eg 
probiotic products for children for controlling diarrhea resulted from antibiotic treatment (Franz et al., 2011; Surawicz, 2003). Thus there is lots of research offer has been done for selective and distinguish between the food grade and pathogenic strains of enterococci. Research group indicate the smaller genome size of the enterococci probiotics compared with pathogenic enterococci (Bonacina et al., 2017).

Among Enterococcus the E. faecium strains have been used as cheese starters or probiotics in human and animal health promotion to improve the intestinal microbial balance (Franz et al., 2011; Yang et al., 2014). Actually, some E. faecium strains are currently in use as therapeutic treatments marketed as Cylactins (Hoffmann-La Roche, Basel, Switzerland), Fargo 688 s (Quest International, Naarden, the Netherlands), and ECOFLOR (Walthers Health Care, Den Haag, the Netherlands) designed for relieving the signs of irritable bowel disease. These products had been tested clinically and approved their effectiveness in several digestive, inflammatory, and neurodegenerative sicknesses (Suvorov et al., 2003; Lo Skiavo et al., 2013; Suvorov, 2013; Baryshnikova et al., 2015; Rho et al., 2017; Holzapfel et al., 2018; Suvorov et al., 2019). Furthermore, enterococci have known for bacteriocins with wide spectrum antimicrobial activity towards both the Gram-positive and negative microbes (Laukova et al., 2017). In addition to their ability to prevent sporulating bacteria such as $C$. botulinum and B. cereus and in some case they may inhibit endospores (Grande Burgos et al., 2014). Furthermore, some enterococcus bacteriocins (often named "enterocins") retain antifungal and/or antiviral action (Hanchi et al., 2018). Their antiviral could be due via direct interaction with the virus and/or by activation of the immune system. Wang et al. (2013) reported the inhibition ability of $E$. faecium NCIMB 10415 strain against influenza viruses via direct contact.

Prevention and alternative treatment are needed to face the emergence of new infectious viruses and increased resistance against the available antiviral drugs.

E. faecium NM213 (accession no. KC878685) is a potential probiotic strain which isolated previously in our laboratory from healthy Egyptian infants according to its immounodolatory properties by in vitro analysis (Mansour et al., 2014). E. faecium NM213 showed ability for stimulation the human immune cells by inducing IL-6 and TNF in mononuclear cells isolated from healthy human donors. Furthermore, it activated the human mono dendritic cells by the release of four diverse cytokines; the IL-1b, the chemotactic CXCL-8, IL-6, which has both pro- and anti-inflammatory actions and the strong TH1 polarizer IL-12. Also it showed strong activation to Toll-like receptor 2. Furthermore, it showed an acceptable safety pattern by expressing sensitive to vancomycin, chloramphenicol, tetracycline and erythromycin in addition to the absence of the major enterococcal virulence genes from its genomic DNA.

This study tests the ability of our strain E. faecium NM213 as antiviral against four type of human viruses; Rotavirus, Hepatitis A Virus (HAV), Coxsackie B4 Virus and herpes simplex virus type-1 (HSV-1). Furthermore, detection and identification of the enterococin genes within its genomic DNA has been done by PCR and sequencing analysis.

\section{Materials and Methods}

\subsection{Preparation of bacterial cell-free supernatant (CFS) and bacterial cell extracts (CE)}

E. facieumNM213 was grown in $30 \mathrm{~mL}$ MRS broth for $24 \mathrm{~h}$ at $37^{\circ} \mathrm{C}$. The culture contain $10^{9}$ $\mathrm{CFU} / \mathrm{ml}$ was centrifuged at $3,000 \mathrm{~g}$ for $15 \mathrm{~min}$. The supernatant was collected and adjusted to $\mathrm{pH} 7.0$ using $1 \mathrm{M}$ sodium hydroxide solution then filter-sterilized $(0.22-\mu \mathrm{m}$ pore size, Merck Millipore, Burlington, MA) and marked as (CFS). The CE was prepared by washing the pellet of bacteria obtained above twice with sterile Phosphate-buffered saline (PBS) to remove excess MRS followed by centrifugation at $3,000 \mathrm{~g}$ for $15 \mathrm{~min}$. The washed pellet was re-suspended in $10 \mathrm{~mL}$ of PBS. The colony forming units (CFUs)/mL were determined using the plate count technique on MRS agar plates.

\subsection{Cytotoxicity test}

The Cytotoxicity test for CFS and CE of E. facieumNM213 was carried by means of cell morphology assessment via inverted light microscope (Simões et al., 1999) and cell viability investigation through trypan blue dye exclusion technique then viable cells were counted by the phase contrast microscope (Walum et al., 1990). The MA104, BGM, FRHK4, and Vero cell lines were provided by vacsera (the Holding Company for Biological Products \& Vaccines VACSERA, Egypt) and the non-toxic dose of the tested samples on the cell lines was evaluated. 
2.3 Determination of rotavirus Wa strain, HAV HM175, Coxsackievirus B4, and herpes simplex virus type 1 titers using plaque assay

Non-toxic dilutions were mixed $(100 \mu \mathrm{l})$ with $100 \mu$ l of different doses of rotavirus Wa strain, HAV HM175, Coxsackievirus B4 and Herpes simplex virus type $1\left(1 \times 10^{5}, 1 \times 10^{6}, 1 \times 10^{7}\right)$. The infectivity of the rotavirus stocks were activated with $10 \mu \mathrm{g} / \mathrm{ml}$ trypsin for $30 \mathrm{~min}$ at $37^{\circ} \mathrm{C}$. The mixture was incubated for $1 / 2 \mathrm{hr}$ in $37^{\circ} \mathrm{C}$. The inoculation of $(100 \mu \mathrm{l}) 10$ fold dilutions of treated and untreated rotavirus $\mathrm{Wa}$ strain, HAV HM175, Coxsackievirus B4 and Herpes simplex virus type 1 was carried out separately into MA104, FRHK4, and BGM cell lines for rotavirus Wa strain, HAV HM175, Coxsackievirus B4, and Herpes simplex virus type 1 respectively in 12 multi well plates. The plates were incubated $1 \mathrm{hr}$ at $37^{\circ} \mathrm{C}$ for adsorption in a $5 \% \mathrm{CO}_{2}$ water vapor atmosphere with occasionally rocking to avoid drying the cells. After adsorption, $1 \mathrm{~mL}$ of $2 \mathrm{X}$ media (Dulbecco's Modified Eagle Medium, Gibco- BRL (DMEM) plus $1 \mathrm{ml} 1 \%$ agarose was added to each well, $0.5 \mu \mathrm{g} / \mathrm{ml}$ was added to the media-agarose mixture in the case of rotavirus Wa strain and the plates were incubated at $37^{\circ} \mathrm{C}$ in a $5 \% \mathrm{CO} 2$-water vapor atmosphere. Then the cells were fixed with formaline and stained with $0.4 \%$ crystal violet, in addition the number of plaques counted. The viral titers were then determined, and stated as plaque-forming units per milliliter (pfu/mL) (Schmidtke et al., 1998).

\subsection{DNA extraction and PCR}

DNA was extracted from bacterial cultures using the AxyPrep bacterial genomic DNA miniprep kit (Axygen Biosciences, Union City, CA, USA) according to the manufacturer's instructions.

PCR was carried out on a thermal cycler system BioRad T100 (Bio Rad, Hercules, CA, USA) using PCR Master Mix (Fermentas Life Sciences, Vilnius, Lithuania), and primers were obtained from (Bioserve, Cairo, Egypt). For purification, a QIAquick PCR purification kit (Qiagen, Hilden, Germany) was used according to the manufacturer's instructions.

\subsection{Detection the presence of the $\boldsymbol{E}$. faecium NM213 enterocin encoding genes}

Genomic DNA of E. faecium NM213 was screened for enterocin A, B, P, and L50A genes by PCR using enterocin-specific primers (du Toit et al., 2000; De Vuyst et al., 2003; Cintas et al., 1997; Cintas et al., 1998). The presence and molecular size of the PCR products were analyzed by electrophoresis on $2 \%$ agarose gels, stained with ethidium bromide and visualized under UV illumination.

Purified PCR products were sequenced using BigDye Terminator v1.1 Cycle Sequencing Kit (Applied Biosystems, Waltham, MA) as directed in the manufacturer's protocol. The resulting sequence data were analyzed using Molecular Evolutionary Genetic Analysis version 7 (MEGA7) (Kumar et al., 2016; Altschul et al., 1990).

\section{Results}

\subsection{A cytotoxicity test}

The cytotoxicity test showed no toxic effect of E. faecium NM213 CFS or CE at dilutions up to $40 \%$ on MA104, Hep2, BGM, and Vero cell lines at concentrations of $10^{5}$ to $10^{7} \mathrm{CFU} / \mathrm{ml} 1$ (data not shown). Their effect onto the viability of MA104, Hep2, BGM, Vero cell lines was evaluated at a concentration of $10^{5}, 10^{6}$, and $10^{7} \mathrm{CFU} / \mathrm{ml}$, the integrity of monolayers was unaltered (data not shown). Moreover, MTT assay indicated no reduction of cell proliferation compared to control (data not shown).

\section{2 in vitro antiviral activity of $E$. faecium $\mathrm{NM213}$ (CFS) and (CE)}

The neutralized CFS and CE from overnight culture E. faecium NM213 $\left(10^{9} \mathrm{CFU} / \mathrm{ml}\right)$ were tested for their antiviral activity against the four proposed viruses the experiments have done in triplets using $10 \%(\mathrm{v} / \mathrm{v})$ dilution from each. CFS and CE showed reduction of the four viruses replication compared to two controls (virus-infected cells with PBS buffer) and (virus-infected cells with MRS). CFS showed $53.3 \%$ inhibition of virus replication Coxsackie B4 while CE showed $10 \%$ as presented in Figure 1, on Hepatitis A Virus (HAV) Strain HM175 CFS and CE showed 60\% and $10 \%$ reduction respectively in Figure 2, while they showed reduction rotavirus Wa to $50 \%$ by CFS and $20 \%$ by CE in Figure 3. The Data shown in Figure 4 display the reduction of herpes simplex virus type-1 (HSV-1) to $70 \%$ by CFS and $20 \%$ by CE. 


\section{Coxsackievirus B4}

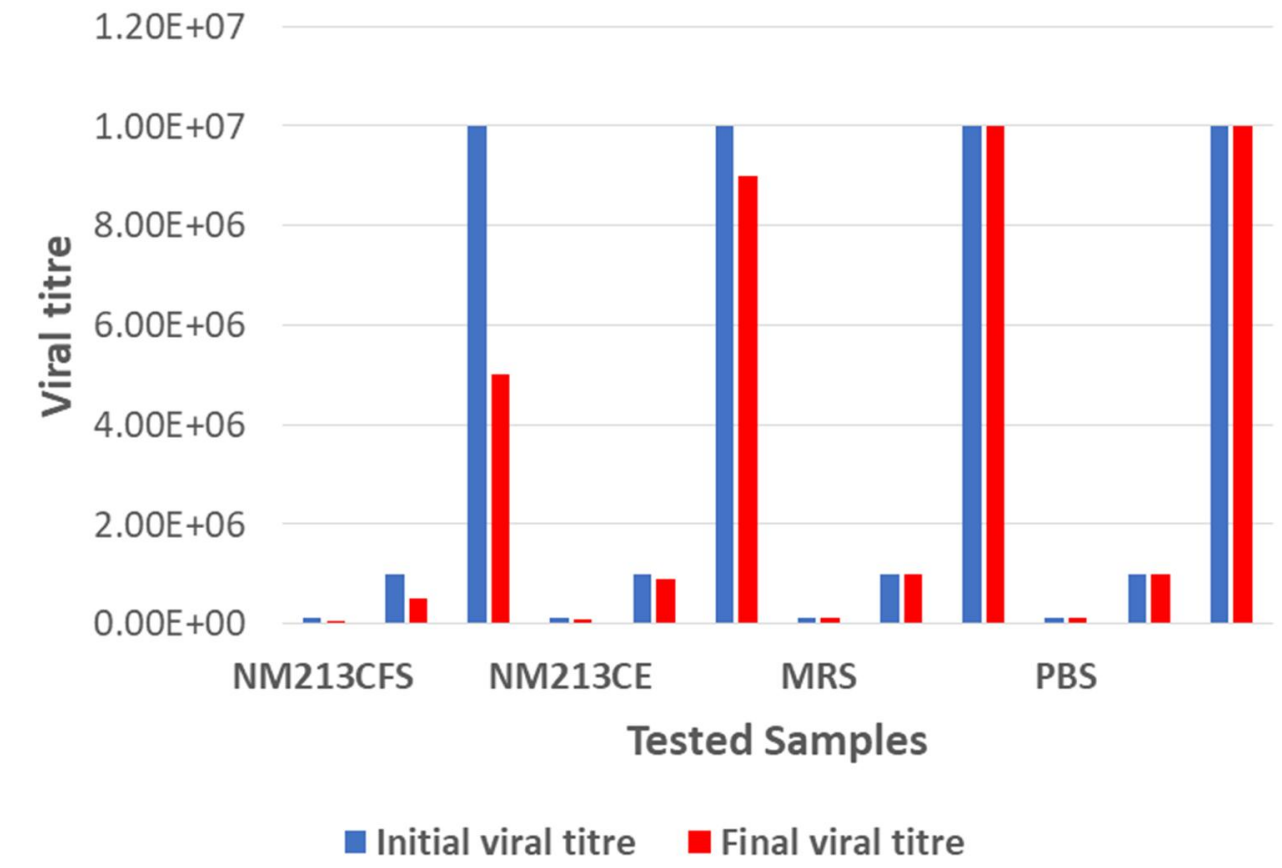

Fig. 1: In vitro antiviral activity of E. faecium NM213 (Culture free supernatant CFS and Cell-free extract CE) against Coxsackievirus B4 compared to the controls; MRS and PBS. Viral titers were analyzed by titration in BGM cell lines. The Blue column shows the initial viral titer and the Red column shows the final viral titer.

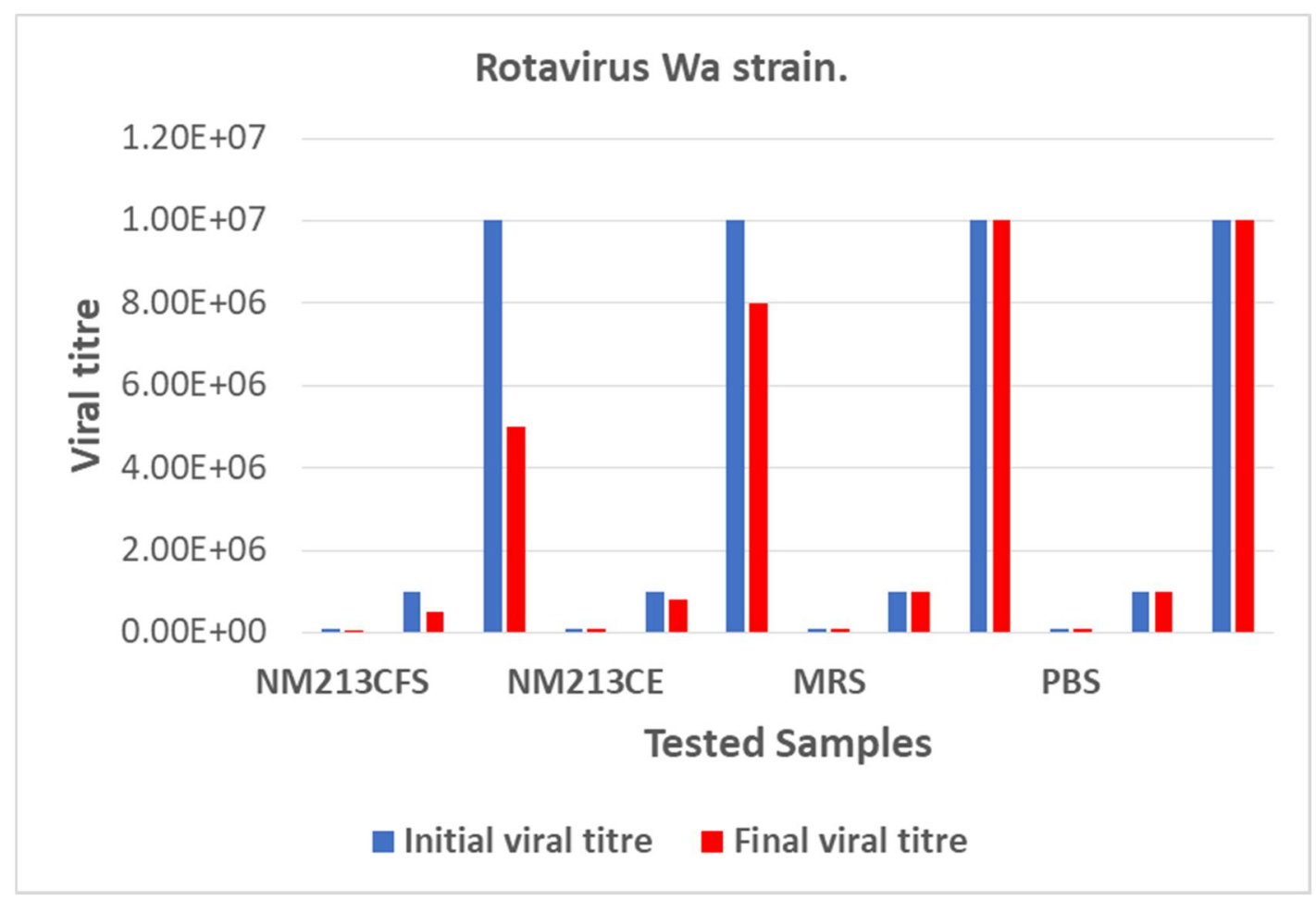

Fig. 2: In vitro antiviral activity of E. faecium NM213 (Culture free supernatant CFS and Cell-free extract CE) against Rotavirus Wa compared to the controls; MRS and PBS. Viral titers were analyzed by titration in MA104 cell lines. The blue column shows the initial viral titer and the red column shows the final viral titer. 


\section{HAV HM 175 strain}

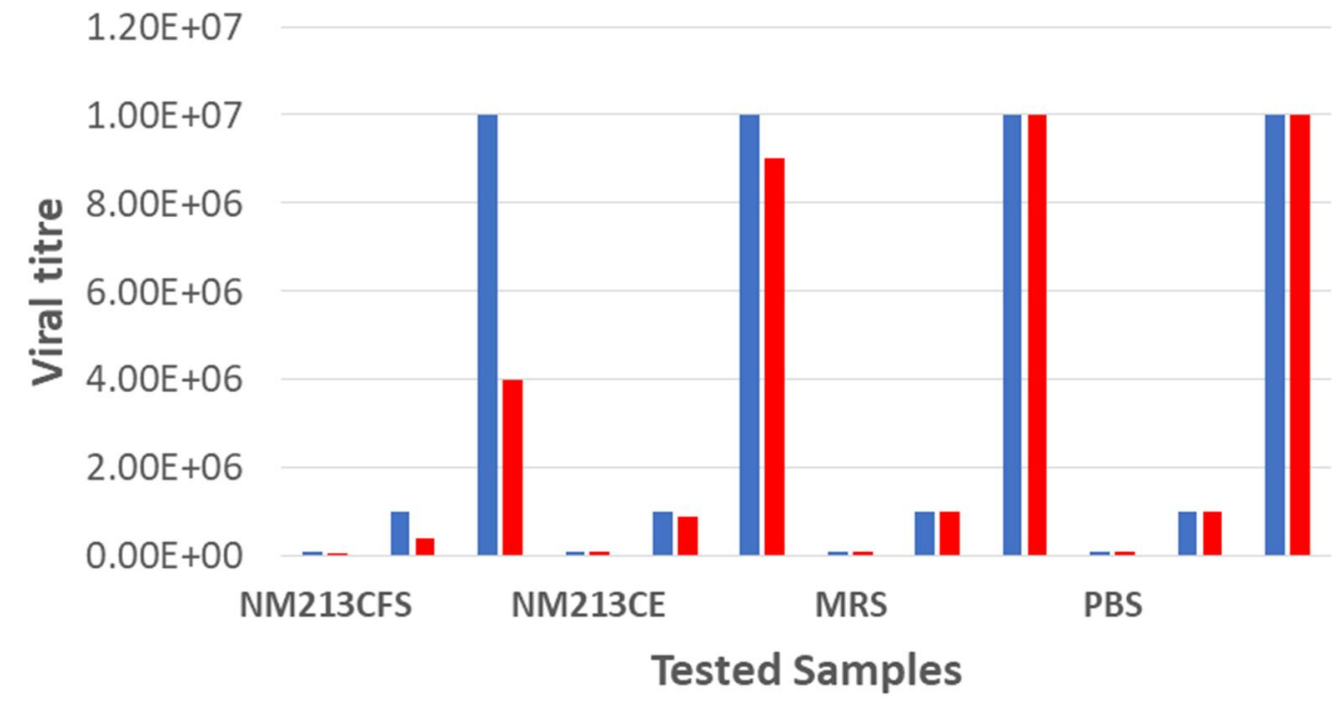

\section{Initial viral titre $\quad$ Final viral titre}

Fig. 3: In vitro antiviral activity of E. faecium NM213 (Culture free supernatant CFS and Cell-free extract CE) against Hepatitis A virus (HM 175) compared to the controls; MRS and PBS. S stands for CFS while C stands for CS. Viral titers were analyzed by titration in FRHK4 cell lines. The blue column shows the initial viral titer and the red column shows the final viral titer.

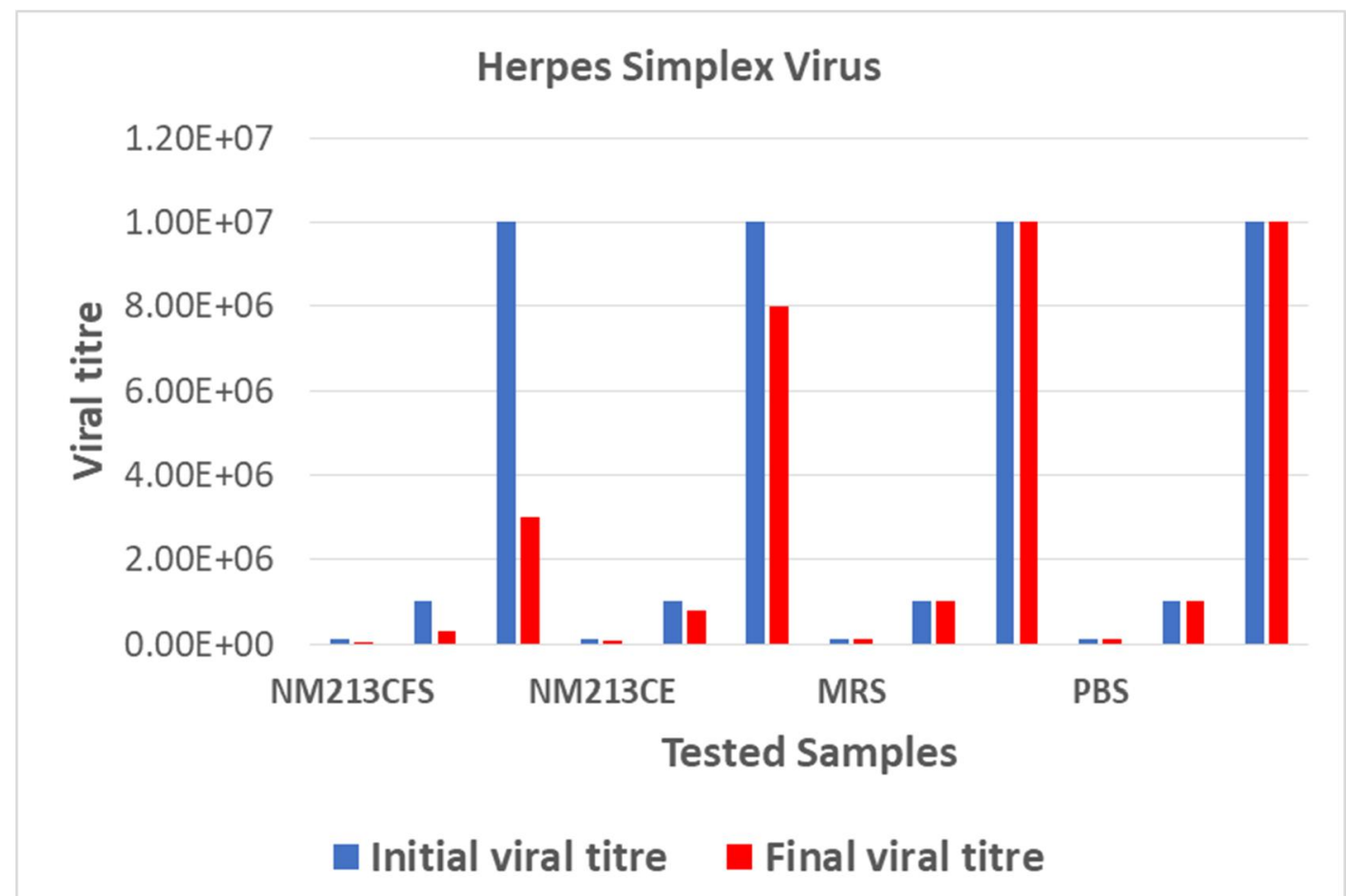

Fig. 4: In vitro antiviral activity of E. faecium NM213 (Culture free supernatant CFS and Cell free extract CS) against Herpes simplex virus type 1 compared to the controls; MRS and PBS. S stands for CFS while C stands for CS. Viral titers were analyzed by titration in Vero cell lines. The blue column shows the initial viral titer and the red column shows the final viral titer. 


\subsection{Detection of the enterocin encoding genes within the genome of $E$. faecium NM213}

The detection of the possible enterocins genes in the NM213 strain was done by PCR amplification using specific primers for the presence of the known enterocin genes ent $\mathrm{A}$, ent $\mathrm{B}$, ent $\mathrm{P}, \mathrm{L} 50 \mathrm{~A}$ as presented in Table (1). Amplifications revealed only two bands with ent $\mathrm{A}$ and ent $\mathrm{B}$ genes with size 475 and 200 bp respectively and no bands obtained for the L50 gene.

The analysis sequencing of the two fragments using blast search at NCBI server revealed the $100 \%$ identical with the enterocin genes encoding by ent $\mathrm{A}$ and ent $\mathrm{B}$ from many Enterococcus faecium strains which available at the NCBI data base.

Table 1: Primers sequence for detecting the enterocin genes

\begin{tabular}{cll}
\hline Primer name & Primer sequence 5-3 & \multicolumn{1}{c}{ References } \\
\hline EntA F & AAATATTATGGAAATGGAGTGTAT & \multirow{2}{*}{ du Toit et al., (2000) } \\
EntA R & CTCGTTAAGGTCCCTTCACG & \multirow{2}{*}{ De Vuyst et al., (2003) } \\
\hline EntB F & CAAAATGTAAAAGAATTAAGTACG & \multirow{2}{*}{ Cintas et al., (1997) } \\
EntB R & AGAGTATACATTTGCTAACCC & \multirow{2}{*}{ Cintas et al., (1998) } \\
EntP F & ATGAGAAAAAAATTATTTAGTT & \\
EntP R & TTAATGTCCCATACCTGCCAAACC & \\
\hline L50AF & ATG GGA GCA ATCGCA AAA TTA & \\
L50AR & TTT GTT AAT TGCCCA TCC TTC &
\end{tabular}

\section{Discussion}

There is a great interest about the vital role of the human microbiome in maintaining its health and discovering the interactions between microbiome and invading microbes. Actually, a healthy microbiome in addition to its metabolites products is crucial for protecting the host from a diversity of pathogenic contagions via direct exclusion and indirect suppression (Piewngam et al., 2018; Kim et al., 2017; Sassone-Corsi et al., 2016; Schuijt et al., 2016). Viruses are one of the most common invaders which interact with the commensal microbes of the hosts throughout their infection routes. There is an evidence has been shown that the microbiome regulates the viruses and is regulated by viruses through several mechanisms which ended by destructive or beneficial effects for the host (Karst, 2016; Pfeiffer \&Virgin, 2016; Berger \& Mainou, 2018). Microbiome shows critical roles in the regulation the viral infection, in addition to utilize substantial inhibitory effects. Reviews describing the role of microbiome in regulation viral infections are available (Karst, 2016; Pfeiffer \&Virgin, 2016; Robinson \& Pfeiffer, 2014; Sullender \& Baldridge, 2018).

The probiotic bacteria have been suggested as alternative means of antiviral treatment(Chai et al., 2013; Kwak et al., 2013; Lee et al., 2013; Kim et al., 2014; Lehtoranta et al., 2014). Their action could be through neutralizing viruses (Rolfe, 2000; Minocha, 2009; Preidis et al., 2011; Zhang et al., 2013) [43-46] or promote the innate immune response and stimulate cellular multiplication of epithelial cells (Preidis et al., 2011; Sur et al., 2011). Wang et al. (2013) confirmed the antiviral effect of E. faecium strain in vitro experiments using porcine H1N1- and H3N2-influenza virus in MDBK- and D4/21 cells.

The probiotic bacterium E. faecium NM213 was isolated from Egyptian infant stool in our laboratory and demonstrated remarkable immunomodulatory abilities in vitro by releasing of the cytokines IL-1b, CXCL-8, IL-6 and IL12 which suggested it as potential for preventing atopic diseases (Mansour et al., 2014), here we aimed to investigate its ability against four viruses.

When we evaluated the antiviral ability of the cell free supernatant of E. faecium NM213 against the four viruses Rotavirus, Hepatitis A Virus (HAV), Coxsackie B4 Virus and herpes simplex virus type-1 (HSV-1) using relevant cell lines as stated at the Methods section the results confirmed its ability to reduce the viruses: (HSV-1), HAV HM 175, Coxsackie (B4), and rotavirus (Wa) by 70\%, 60\%, $53.3 \%$, and $50 \%$ respectively.

Furthermore, studies have shown that enterocins secreted by enterococcus has antimicrobial properties against Gram positive and Gram negative bacteria (Hanchi et al., 2018). A few studies have stated the antiviral effect of enterocins through the production of antimicrobial molecules such as Enterocin CRL35 which produced by Enterococcus faeciumCRL35 and expressed antiviral activity against thymidine-kinase positive and deficient strains of herpes simplex (HSV) type 1 and 2 in and BHK-21 cells(Wachsman et al., 1999), Ent. faecium ST5Ha secrets a pediocin-like bacteriocin showed high activity against HSV-1 virus in addition to other pathogens (Todorov et al., 2010). However, 
screened the genome of the E. faecium NM213 for the presence of the antimicrobial by PCR targeting common enterocoin genes, the results showed that presence of only ent $\mathrm{A}$ and ent $\mathrm{B}$ genes. Taking together, antiviral activity, the immunomodulatory properties in addition to detection two enterocoin genes make this strain is valuable and looking for further analysis to introducing it for industrial purpose.

\section{Conclusion}

In conclusion, here we present the in vitro antiviral activity of $E$. faecium NM213 against the main human viruses; Rotavirus, Hepatitis A Virus (HAV), Coxsackie B4 Virus and herpes simplex virus type-1 (HSV-1). Furthermore, the detection of enterocoins revealed the presence of two enterocins genes encoding ent $\mathrm{A}$ and ent $\mathrm{B}$ within its genome. Thus more attention should be given for characterization for probiotic purposes. We are working to translate these in vitro findings to in vivo experiment on mice. In addition, doing complete genome sequence and molecular characterization of the bacterium to be satisfied with it is safe.

\section{Acknowledgements}

This research was supported by the National Research Centre, Cairo - Egypt.

\section{Declarations}

\section{Funding \\ 'Not applicable' \\ Conflicts of interest}

The authors declare that there is no conflict of interests

\section{Availability of data and material}

All relevant data are included within the paper

\section{Code availability (software application or custom code) 'Not applicable'}

\section{Authors' contributions}

All authors contributed to the study conception and design. Material preparation, data collection and analysis were performed by Nahla M Mansour, Hayam Mansour, Ahmed I Abd El Naem, and Waled M Elsenousy. The first draft of the manuscript was written by Nahla M Mansour and all authors commented on previous versions of the manuscript. All authors read and approved the final manuscript.

\section{References}

Altschul, S.F., W. Gish, W. Miller, E.W. Myers, and D.J. Lipman, 1990. Basic local alignment search tool. J. Mol. Biol., 215:403-410 10.1016/S0022-2836(05)80360-2.

Baryshnikova, N.V., Y.P. Uspenskiy, A.N. Suvorov, A.V. Svarval, and A.B. Zebrun, 2015. In vitro efficacy of certain probiotic strains in inhibition growth of $\mathrm{H}$. pylori. Conference paper in Helicobacter, 20:95-95 www.helicobacter.org9.

Berger, A.K. and B.A. Mainou, 2018. Interactions between enteric bacteria and eukaryotic viruses impact the outcome of infection. Viruses, 10:19. 10.3390/v10010019.

Bonacina, J., N. Suárez, R. Hormigo, S. Fadda, M. Lechner and L. Saavedra, 2017. A genomic view of food-related and probiotic Enterococcus strains. DNA Res., 24(1):11-24. https://doi.org/10.1093/dnares/dsw043.

Chai, W., M. Burwinkel, Z. Wang, et al., 2013. Antiviral effects of a probiotic Enterococcus faecium strain against transmissible gastroenteritis coronavirus. Arch. Virol., 158:799-807.

Cintas, L.M., P. Casaus, H. Holo, P.E. Hernandez, I.F. Nes and L.S. Havarstein, 1998. Enterocins L50A and L50B, two novel bacteriocins from Enterococcus faecium L50 are related to staphylococcal haemolysins. J Bacteriol 180:1988-1994. 
Cintas, L.M., P. Casaus, L.S. Havarstein, P.E. Hernándéz, and I.F. Nes, 1997. Biochemical and genetic characterization of enterocin P, a novel sec-dependent bacteriocin from Enterococcus faecium P13 with a broad antimicrobial spectrum. Appl Environ Microb., 63:4321-4330.

De Vuyst, L., M.R. Foulquié Moreno, and H. Revets, 2003. Screening for enterocins and detection of hemolysin and vancomycin resistance in enterococci of different origins. Int. J. Food Microbiol., 84(3):299-318. doi: 10.1016/s0168-1605(02)00425-7.

Devriese, L.A., B. Pot, L. van Damme, K. Kersters, and F. Haesebrouck, 1995. Identification of Enterococcus species isolated from foods of animal origin. Int. J. Food Microbiol., 26:187-197.

du Toit, M., C.M. Franz, L.M. Dicks and W.H. Holzapfel, 2000. Preliminary characterization of bacteriocins produced by Enterococcus faecium and Enterococcus faecalis isolated from pig faeces. J Appl Microbiol. 88:482-494. https:// doi .org/ 10 .1046/ j .1365-2672 .2000 .00986.

Franz, C.M.A.P., M. Huch, H. Abriouel, W. Holzapfel, and A. Gálvez, 2011. Enterococci as probiotics and their implications in food safety. Int. J. Food Microbiol., 151:125-140.

Gomes, B.C., C.T. Esteves,\& I.C.V. Palazzo, et al., 2008. Prevalence and characterization of Enterococcus spp. Isolated from brazilian foods. Food Microbiol., 25:668-675.

Grande Burgos, M.J., R.P. Pulido, M. Del Carmen Lopez Aguayo, A. Galvez and R. Lucas, 2014. The cyclic antibacterial peptide enterocin AS-48: isolation, mode of action, and possible food applications. Int J Mol Sci 15:22706-22727.

Hanchi, H., W. Mottawea, K. Sebei and R. Hammami, 2018. The Genus Enterococcus: Between Probiotic Potential and Safety Concerns-An Update. Front. Microbiol., 9:1791. doi: 10.3389/fmicb.2018.01791.

Holzapfel, W., A. Arini, M. Aeschbacher, R. Coppolecchia, and B. Pot, 2018. Enterococcus faecium SF68 as a model for efficacy and safety evaluation of pharmaceutical probiotics. Benef. Microbes, 9(3):375-388.https://doi.org/10.3920/BM2017.01486.

Karst, S.M., 2016. The influence of commensal bacteria on infection with enteric viruses. Nat Rev Microbiol., 14:197-204. 10.1038/nrmicro.2015.25.

Kim, M.J., D.K. Lee, J.E. Park, I.H. Park, J.G. Seo, and N.J. Ha, 2014. Antiviral activity of Bifidobacterium adolescentis SPM1605 against Coxsackie virus B3. Biotechnol Equip., 28:681688.

Kim, Y.G., K. Sakamoto, S.U. Seo, et al., 2017. Neonatal acquisition of Clostridia species protects against colonization by bacterial pathogens. Science 356:315-319.

DOI: https://doi.org/10.1126/science.aag2029, PMID: 28428425.

Kumar, S., G. Stecher, and K. Tamura, 2016. MEGA7: Molecular Evolutionary Genetics Analysis version 7.0 for bigger datasets. Mol Biol Evol., 33:1870-1874.

Kwak, M.K., R. Liu, J.O. Kwon, M.K. Kim, A.H. Kim and S.O. Kang, 2013. Cyclic dipeptides from lactic acid bacteria inhibit proliferation of the influenza a virus. J. Microbiol., 51:836-843.

Laukova, A., A. Kandricakova, L. Bunkova, P. Pleva and J.Scerbova, 2017. Sensitivity to enterocins of biogenic amine-producing faecal Enterococci from ostriches and pheasants. Probiotics Antimicrob. Proteins 9:483-491.

Lee, D.K., J.Y. Kang, H.S. Shin, I.H. Park, and N.J. Ha, 2013. Anti-viral activity of Bifidobacterium adolescentis SPM0212 against hepatitis B virus. Arch. Pharm 36:1525-1532.

Lehtoranta, L., A. Pitkäranta, and R. Korpela, 2014. Probiotics in respiratory virus infections. Eur J Clin Microbiol Infect Dis., 33:1289-1302.

Lo Skiavo, L.A., N.V. Gonchar, M.S. Fedorova, and A.N. Suvorov, 2013. Dynamics of contamination and persistence of Clostridium difficile in intestinal microbiota in newborn infants during antibiotic therapy and use of probiotic strain Enterococcus faeciumL3. Antibiot Khimioter, 58(11-12):131810.

Mansour, N.M., H. Heine, S.M. Abdou, M.E. Shenana, M.K. Zakaria, and A. El-Diwany, 2014. Isolation of Enterococcus faecium NM113, Enterococcus faecium NM213 and Lactobacillus casei NM512 as novel probiotics with immunomodulatory properties. Microbiol Immunol., 58: 559-569.

Minocha, A., 2009. Probiotics for preventive health. Nutrition in Clinical Practice. 24:227-241. 
Pesavento, G., C. Calonico, B. Ducci, A. Magnanini, and A. Lo Nostro, 2014. Prevalence and antibiotic resistance of Enterococcus spp. isolated from retail cheese, ready-to-eat salads, ham, and raw meat. Food Microbiol., 41:1-7.

Pfeiffer, J.K. and H.W. Virgin, 2016. Viral immunity. Transkingdom control of viral infection and immunity in the mammalian intestine. Science 351:5872. 10.1126/science.aad5872.

Piewngam, P., Y. Zheng, T.H. Nguyen, et al., 2018. Pathogen elimination by probiotic Bacillus via signalling interference. Nature. 562:532-7.

Preidis, G.A., C. Hill, R.L. Guerrant, B.S. Ramakrishna, G.W. Tannock, and J. Versalovic, 2011. Probiotics, enteric and diarrheal diseases, and global health. Gastroenterol, 140:8-14.

Rho, M.K., Y.E. Kim, H.I. Rho, et al., 2017. Enterococcus faecium FC-K derived from Kimchi is a probiotic strain that shows anti-allergic activity. J Microbiol Biotechn, 27(6):1071-1077.

Robinson, C.M. and J.K Pfeiffer, 2014. Viruses and the microbiota. Annu. Rev. Virol., 1:55-69. 10.1146/annurev-virology-031413-085550.

Rolfe, R.D., 2000. The role of probiotic cultures in the control of gastrointestinal heath. J. Nutr., 130:396S-402S.

Sassone-Corsi, M., S.P. Nuccio, H. Liu, et al., 2016. Microcins mediate competition among Enterobacteriaceae in the inflamed gut. Nature, 540:280-283.

Schmidtke, M., C. Knorre, L. Blei, A. Stelzner and E. Birch-Hirschfeld, 1998. Penetration and Antiviral Activity of Coxsackievirus B3 (Cvb3)-Specific Phosphorothioate Oligodeoxynucleotides (Ps-Odn). Nucleosides Nucleotides, 17: 1557-1566.

Schuijt, T.J., J.M. Lankelma and B.P. Scicluna, et al., 2016. The gut microbiota plays a protective role in the host defence against pneumococcal pneumonia. Gut., 65:575-83.

Simões, C.M.O., M. Amoros, and L. Girre, 1999. Mechanism of antiviral activity of triterpenoid saponins. Phytother Res., 21:317-325.

Sullender, M.E. and M.T. Baldridge, 2018. Norovirus interactions with the commensal microbiota. PLoS Pathog., 14:e1007183. 10.1371/journal.ppat.1007183.

Sur, D., Manna B., Niyogi S.K., et al., 2011. Role of probiotic in preventing acute diarrhoea in children: a community-based, randomized, double-blind placebo-controlled field trial in urban slum. Epidemiol Infect., 139:919-926.

Surawicz, C.M., 2003 Probiotics, antibiotic-associated diarrhoea and clostridium difficile diarrhoea in humans. Best Pract Res Cl Ga., 17:775-783.

Suvorov, A., 2013. Gut microbiota, probiotics, and human health. Biosci Microb Food H, 32:81-91. doi:https://doi.org/10.12938/bmfh.32.815.

Suvorov, A., E. Ermolenko, G. Alechina, A. Chernysh, A. Karaseva, AND F. Di Pierro, 2019. Enterococcus as probiotics: what is the advantage? Nutrafoods, 1:17. https://doi.org/10.17470/NF-019-00037.

Suvorov, A.N., S.M. Zaharenko and G.G. Alekhina, 2003. Enterococci as probiotics of choice. Clin Nutr., 1:26-298.

Todorov, S.D., M.Wachsman, and E. Tomé, et al., 2010. Characterisation of an antiviral pediocin-like bacteriocin produced by Enterococcus faecium. Food Microbiol 27(7):869-879.

Wachsman, M.B., M.E. Farias, and E.T akeda, et al., 1999. Antiviral activity of enterocin CRL35 against herpesviruses. The Int J Antimicrob Agents, 12:293-9.

Walum, E., K. Strenberg, and D. Jenssen, 1990. Understanding Cell Toxicology: Principles and Pratice, Ellis Howood, NewYork, p. 97-111.

Wang, Z., W. Chai and M. Burwinkel, et al., 2013. Inhibitory Influence of Enterococcus faecium on the Propagation of Swine Influenza A Virus In Vitro. PLoS One 8(1): e53043. doi:10.1371/journal.pone.0053043.

Yang, S.C., C.H. Lin, C.T. Sung, and J.Y. Fang, 2014. Antibacterial activities of bacteriocins: application in foods and pharmaceuticals. Front. Microbiol., 5:241. https://doi.org/10.3389/fmicb.2014.00241.

Zhang, H., J. Sun, X. Liu, et al., 2013. Lactobacillus paracasei subsp. paracasei LC01 positively modulates intestinal microflora in healthy young adults. J Microbiol., 51:777-782. 